\title{
El teatro en la enseñanza de lenguas extranjeras La dramatización como modelo y acción
}

\author{
Anna CORRAL FULLÀ ${ }^{1}$ \\ Universidad Autónoma de Barcelona \\ Departamento de Filología Francesa y Románica \\ ana.corral@uab.cat
}

Recibido: noviembre 2011

Aceptado: diciembre 2012

\section{RESUMEN}

El teatro en la enseñanza de una lengua extranjera representa uno de los recursos más estudiados y explotados en el aula, lo cual queda suficientemente manifiesto en los numerosos estudios y análisis a favor y en contra de su práctica como herramienta pedagógica. El presente artículo pretende adentrarse en los distintos modos de aplicación de este recurso en el aprendizaje de una lengua extranjera partiendo de un doble enfoque: el teatro como acción -rol activo del alumno como actor- versus el teatro como modelo -el estudiante tiene el papel de receptor/espectador. En la primera parte del artículo, nos centraremos en las distintas prácticas teatrales en el aula: representación de una obra teatral o elaboración de los muy recurridos juegos de simulación. Seguidamente, para abordar el teatro como modelo sociocultural y lingüístico, analizaremos uno de los primeros materiales elaborados para la enseñanza del español como lengua extranjera a través de la dramatización, la serie Hablamos Español.

Palabras clave: enseñanza, lengua, extranjera, teatro, dramatización.

\section{Theatre used in teaching foreign languages Dramatisation as a model and action}

\begin{abstract}
Using theatre in foreign language teaching is one of the most studied and exploited strategies in the classroom. This has been clearly documented in the many studies that have been carried out, both advocating and criticising its practical use as a pedagogical tool. This article attempts to delve further into the various methods which apply the theatre genre to learning a foreign language and works from the basis of two perspectives: the theatre as "action" -the active role of the student as an actor- contrasted with the theatre as a "model" -the student plays a role as language receiver and spectator. The first part of this article focuses on various theatre practices in the classroom: representing a play and resorting to commonly used simulation games. Later, seeing theatre as a socio-cultural and linguistic
\end{abstract}

${ }^{1}$ Esta investigación ha estado en parte financiada por el Gobierno Catalán 2009SGR700 
model, this article analyses one of the primary teaching materials designed for teaching Spanish as a foreign language, namely, the series Hablamos Español.

Keywords: teaching, foreign language teaching, theatre, dramatisation.

\title{
Le théâtre dans l'enseignement des langues étrangères La dramatisation comme modèle et action
}

\begin{abstract}
RESUME
Le théâtre représente l'une des ressources les plus étudiées et exploitées dans l'enseignement/apprentissage d'une langue étrangère, ce qui se manifeste largement dans les nombreuses études et analyses pour et contre sa pratique comme outil pédagogique. Cet article prétend approfondir les différentes façons d'application de cette ressource dans l'apprentissage d'une langue étrangère à partir d'une double approche: le théâtre comme action -rôle actif de l'étudiant comme acteur- versus le théâtre comme modèle - l'élève assume le rôle de récepteur/spectateur. Dans la première partie de cette étude, nous nous centrerons sur les diverses pratiques théâtrales en classe de langue : représentation d'une pièce de théâtre ou création des jeux de rôles. Ensuite, pour aborder le théâtre comme modèle socioculturel et linguistique, nous analyserons l'un des premiers matériels élaborés pour l'enseignement de l'espagnol langue étrangère à travers la dramatisation, la série télévisée Hablamos Español.
\end{abstract}

Mots clé: enseignement, langue, étrangère, théàtre, dramatisation.

Sumario: 1. Introducción, 2. El teatro como acción en el marco de la enseñanza de lenguas extranjeras. 2.1 La representación teatral o teatro. 2.2 El juego de simulación o drama. 3. Hablamos Español: de la dramatización como modelo sociocultural y lingüístico. 4. Conclusiones. Referencias bibliográficas.

\section{INTRODUCCIÓN}

En los últimos tiempos, existe una proliferación de investigaciones y estudios en el campo de la enseñanza de lenguas extranjeras centrados en la integración de un contenido y una lengua. Se propone la enseñanza de ciertas materias del programa de estudios en una lengua extranjera, lo cual permitiría poner en práctica y mejorar las competencias lingüísticas del alumno partiendo de una inmersión lingüística (CLIL: Content and language integrated learning) (Baetens, 2003; Baker, 2001; Bertaux, 2000; Coyle, 2002). Paralelamente y siguiendo esa misma vía de reagrupación de diversas disciplinas, otros estudios investigan en las posibilidades que algunas manifestaciones artísticas ofrecen al aprendizaje de una lengua extranjera y en la aplicación de los nuevos recursos que se derivan de éstas: la música (Aubin, 1997\&2008; Corral, 2008) o el teatro (Torres Núñez, 1996; Wessels, 2000 [1987]). Este artículo se inscribe en esta segunda línea de investigación y se centra en el análisis de la práctica teatral, en su sentido más amplio, como recurso peda- 
gógico en la enseñanza/aprendizaje de las segundas lenguas. En efecto, hoy en día, esta praxis representa uno de los recursos más estudiados y explotados en el aula, lo cual queda suficientemente manifiesto en los numerosos estudios y análisis a favor y en contra de su práctica como herramienta pedagógica. El presente artículo pretende adentrarse en los distintos modos de aplicación de este recurso en el aprendizaje de una lengua extranjera adoptando una óptica generalista con el objetivo de llevar a cabo una revisión de las distintas prácticas y tareas aplicadas en este campo y analizar sus beneficios i/o eficacia en el proceso de aprendizaje de una lengua extranjera.

El uso del "teatro" como recurso en la enseñanza/aprendizaje de una L2 puede asumir dos papeles bien diferenciados en función del rol asumido por el estudiante: un rol activo en tanto que participante actor, o bien, un rol pasivo como receptor espectador. Este trabajo pretende dejar constancia de ambos procesos en los dos apartados que lo componen en un recorrido que conduce de lo general a lo particular:

(1) "El teatro como acción en el marco de la enseñanza de lenguas extranjeras”: análisis de las distintas prácticas de dramatización en el aula propuestas en los métodos y realizadas por el estudiante/actor.

(2) "Hablamos Español: del teatro como modelo sociocultural y lingüístico": representa un análisis crítico de una de las primeras tentativas del área de la enseñanza del E/LE en este campo. La experiencia se remonta al año 1970 cuando la televisión alemana rodó la serie Hablamos Español, un material enfocado al aprendizaje del español como lengua extranjera a través de diversas situaciones dramatizadas y en el cual el estudiante asume el rol de receptor/espectador.

\section{EL TEATRO COMO ACCIÓN EN EL MARCO DE LA ENSEÑANZA DE LENGUAS EXTRANJERAS}

Dos tipos de prácticas muy distintas en cuanto a la concepción y finalidad de las mismas se distinguen en el seno de las actividades teatrales dirigidas a la enseñanza de lenguas extranjeras: por un lado, la representación de una secuencia o de toda una obra teatral y, por el otro, los conocidos juegos de simulación o de dramatización. Esta división que opone lo que se ha dado en llamar, algo vagamente y no sin vacilaciones, drama versus teatro se basa en la distinción entre proceso y producto acabado: "el drama... supone un proceso de creación -desde jugar juegos como charadas, hasta improvisación y role-playing... El teatro, por otra parte, tiene que ver con la representación. La representación se escenifica y tiene un público pasivo" (Richard Tomlinson en Torres Núñez, 1996: 22-23). Ahora bien, ¿qué significa e implica el concepto de "teatro" aplicado a la Enseñanza de Lenguas Extranjeras?

Se trate de un simple juego dramatizado o de la representación de la secuencia de una obra teatral, sobrepasamos la barrera de un mero ejercicio oral cuando introducimos la teatralización. ¿Pero qué aporta esa teatralización y qué pone en funcionamiento? Podemos hablar de teatro cuando ponemos en movimiento los distin- 
tos lenguajes que participan en el acto comunicativo -la palabra, la voz, el gesto o el movimiento corporal- en una situación creada ficticiamente. Los grandes directores e investigadores teatrales del siglo XX ya pusieron el acento en el hecho de que no es posible separar la palabra de los impulsos que la inspiran ni del cuerpo y voz que la producen. A este respecto, Grotowsky señala "Existe la voz, pero no se puede separar la voz de la palabra, no se puede separar la voz del cuerpo, no se puede separar el cuerpo de las pulsiones y acciones, no se puede separar las pulsiones y acciones del sentido" (en Peter Brook, 2009: 115). Otro gran pedagogo teatral insistía en este mismo concepto del teatro al afirmar que "La gimnasia dramática va acompanyada por una dimensión vocal, ya que sería absurdo pretender separar la voz del cuerpo. Cada gesto posee una sonoridad, una voz, que intento hacerles descubrir a los alumnos. [...]. Con el movimiento puede ser lanzado un sonido, una palabra, una frase, una secuencia poética o un texto dramático” (Lecoq, 2009: 106).

En la dramatización, se requiere del estudiante la representación de un personaje. Éste debe, mediante la imitación, crear las reacciones de otro ser, lo que comporta un trabajo centrado en la interioridad que mueve al personaje y su reflejo en la forma exteriorizada.

El trabajo de la lengua oral a través de la dramatización de situaciones concretas o de la representación de una obra teatral ofrece numerosas posibilidades para abordar tanto aspectos de la competencia lingüística como discursiva, sociolingüística o estratégica. En efecto, la sistematización e integración de la gramática, del léxico, o el trabajo sobre la pronunciación y entonación siempre en armonía con el cuerpo son algunas de las ventajas más visibles. Pero también la motivación que esta práctica puede despertar en los alumnos, el trabajo que se lleva a cabo para vencer la inhibición, o los ejercicios de improvisación pueden ayudar a derribar obstáculos de tipo emocional que también aparecen en el aprendizaje de una lengua extranjera. Por último, en los ensayos, la insistencia y repetición de los diálogos asegura un camino hacia la naturalidad y espontaneidad en la producción de la lengua oral, una espontaneidad que los aprendientes de una lengua extranjera no pueden alcanzar de otro modo en el aula. Boadella, director y dramaturgo de Els Joglars dice respecto a los diálogos de sus obras:

Un punto muy importante en nuestras obras es conseguir que den la sensación de improvisación, que den la impresión de que en aquel momento los actores no se saben un texto de memoria [...] Hay que pasar primero por esta sensación de memorización, sensación que llamamos teatro, esa sensación de teatralización que nosotros vamos lentamente eliminando para dar una sensación de espontaneidad, de improvisación (Boadella en Corral, 2009: 349). 
Es justamente esa espontaneidad "ficticia" la que es posible conseguir en un inicio con los estudiantes. Ahora bien, lo que hoy es ficticio resulta ser una vía que conduce a una producción final más natural y de mayor corrección en todas las competencias que deben ser adquiridas por el alumno. Seguidamente, profundizaremos en todos estos aspectos: ¿Qué posibilidades ofrece el teatro a la enseñanza de lenguas extranjeras y bajo qué condiciones? Para ello, adoptaremos la distinción entre teatro y drama a la que nos hemos referido al inicio de este apartado.

\subsection{La representación teatral o teatro}

El montaje de una obra teatral como modo de aprendizaje de una lengua extranjera no siempre es una práctica bien acogida entre los estudiosos. Hay quien pone en duda su valor pedagógico al considerar que en la repetición de un texto escrito de antemano "las palabras de otras personas que han sido mecánicamente memorizadas se convierten en cenizas en la boca del hablante" (A. Maley y A. Duff en Martínez Cobo, 2007: 143). No obstante, como indica Ana Martínez Cobo "los autores se olvidan de que, en la representación teatral, las palabras [...] no están ni pueden estar muertas, puesto que dependen de la contextualización activa de la escena...” (Martínez Cobo, 2007: 143). En efecto, la afirmación de Maley y Duff muestra un desconocimiento profundo del hecho teatral. Si dirigimos, por un momento, nuestra atención a algunas declaraciones de los grandes directores, dramaturgos e investigadores teatrales del siglo XX, veremos que el argumento ofrecido por Maley y Duff carece de fundamento. En La construcción del personaje, Stanislavski ya insistía en el hecho de que no se puede olvidar "que la obra de teatro impresa no es un trabajo acabado hasta verse representado por actores en un escenario y cobrar vida gracias a emociones humanas auténticas" (1975 [1949]: 141). De hecho, esas palabras que acaban resultando “cenizas” según Maley y Duff deberán convertirse en la palabras propias del actor puesto que para pronunciarlas “debemos disponer de una verdad, aunque sólo sea la verdad de la imaginación, en la que [los actores] pueden creer, dentro de la que pueden vivir" (Stanislavski, 1975 [1949]: 146). De igual modo, Witold Gombrowicz, en la introducción a su obra teatral Opereta señala que "el texto de una pieza contemporánea cada vez se presta menos a la lectura. Cada vez se asemeja más a una partitura, que sólo comienza a vivir en la escena, en la acción, en el espectáculo” (1973 [1966]). Más bien al contrario, las palabras, en una obra teatral, no "se convierten en cenizas" sino que nacen sobre el escenario cargadas de un significado nuevo en cada puesta en escena.

Al margen de estas críticas, la representación de una obra teatral o de tan sólo una secuencia ofrece grandes posibilidades para el aprendizaje de una lengua extranjera. La lengua es trabajada en su globalidad y por lo tanto no se incide en una única estructura gramatical o en el léxico de un centro de interés concreto. Más bien al contrario, una multiplicidad de estructuras y de vocabulario ampliarán de forma substancial la competencia del estudiante. Según Wessels, los ensayos y 
representación final de una obra "ayuda al estudiante a aprender vocabulario nuevo y estructuras de una manera integrada y completamente contextualizada cumpliendo así los objetivos del enfoque comunicativo" (en Torres Núñez, 1996: 56). Pero además, como subraya Leyre Gotilla Pastor

La relevancia de este tipo de ejercicios en el marco de una enseñanza de idiomas comunicativa es indiscutible según autores como Dorrego (1997), puesto que potencia la implicación de los alumnos no solo a nivel intelectual, sino emocional, imaginativo o creativo, además de ayudar a combatir las inhibiciones, la falta de interés y la baja participación que pueden darse en el aula de E/LE. (Gotilla Pastor, 2007: 103).

En efecto, hoy sabemos que el "juego" es fundamental para el desarrollo (Piaget, 1962) tanto en los niños como en los adultos. El teatro no es más que una forma de juego, de ahí que en muchas lenguas "interpretar" se designe con la palabra “jugar”: “jouer” en francés o "to play” en inglés. El teatro permite al estudiante "jugar a ser otro y a liberarse de los roles aprendidos. Y, de esta, forma, el tímido puede convertirse en alguien extrovertido, el seguro en una persona insegura...” (Martínez Cobo, 2007: 147). Pero al mismo tiempo la práctica teatral representa una preparación a la vida puesto que todos desempeñamos uno o distintos papeles en los diferentes ámbitos de nuestras relaciones: el opositor que debe presentar una ponencia oral o el profesor ante sus alumnos son algunos ejemplos entre otros muchos que encontraríamos en las distintas situaciones de la vida diaria. Todos nos cubrimos con las vestimentas propias que nos permiten representar los distintos roles que interpretamos en nuestra vida cotidiana. Jean Genet, en su obra El Balcón, concluye justamente haciendo referencia a las máscaras y papeles que todos representamos en la vida corriente, una actuación aún más ilusoria y simulada que en el propio teatro:

... s'habiller... ah, les déguisements! Redistribuir les rôles... endosser le mien... Elle s'arrête au milieu de la scène, face au public. ... préparer le vôtre... juges, généraux, évêques, chambellans, révoltés qui laissez la révolte se figer, je vais préparer mes costumes et mes salons pour demain... il faut rentrer chez vous, où tout, n'en doutez pas, sera encore plus faux qu'ici (1979 [1956] : 153).

Este hecho me parece capital puesto que el éxito que podamos alcanzar en los distintos ámbitos de nuestra vida dependerá en un alto grado de la capacidad que tengamos de adoptar un papel determinado y de creer en él. De este modo, un estudiante extranjero que interprete un personaje de la literatura dramática española en la lengua original de la obra y que se adentre en la naturaleza propia de éste identificándose con él tendrá grandes posibilidades de integrar muchos de los componentes de las distintas competencias comunicativas de la lengua en contexto: lingüísticas -entonación, pronunciación, léxico, estructuras gramaticales-, gestuales, socioculturales, etc. Pero además, a través de la práctica teatral, esa integración del 
personaje con todas sus particularidades caracterológicas, culturales y lingüísticas se asienta gracias a la propia técnica puesta en marcha en el teatro. La repetición y memorización inherentes a la práctica teatral son unas herramientas excelentes para el aprendizaje de una lengua extranjera: "Se ha comprobado que en los ensayos se puede repetir una y otra vez una palabra o una frase y los alumnos no se cansan. Sin embargo, si ese mismo ejercicio de repetición se hace en clase, ellos no lo aguantan” (Torres Núñez, 1996: 67). Uno de los componentes lingüísticos en los que la práctica de la repetición y memorización ofrece mejores resultados es la pronunciación (Corral, 2008; Hayes, 1984; Wessels, 1987):

Dans l'enseignement/apprentissage des langues étrangères la mémoire doit également aider les étudiants à mieux intégrer les acquis. En fait, la mémorisation de dialogues comme au théâtre permet à l'étudiant d'oraliser le texte d'une manière plus naturelle et globale - matière phonique mais aussi posture corporelle et gestualité- et d'être plus attentif à la prononciation et l'intonation (Corral, 2008: 150).

\section{En la misma línea, Hayes señala que}

Una ventaja de que los estudiantes aprendan sus papeles es que ello les da una oportunidad para concentrarse y trabajar en la voz y en la pronunciación de una forma más interesante que por medio de los “drills" o en clase. Cada expresión se puede examinar desde el punto de vista de la articulación, acento, entonación, etc. y la adecuación del estilo de habla de acuerdo con la situación y el rol desempeñado (1984: 100).

En resumen, el montaje de una obra teatral en el aula de enseñanza de una lengua extranjera posee enormes posibilidades para desarrollar las diferentes competencias comunicativas del estudiante y representa una experiencia completa que integra aspectos cognitivos, físicos y afectivos. No debemos olvidar que el juego teatral conlleva de por sí un alto grado de motivación. Como señala Richard Via "una obra de teatro en inglés es un éxito. Todos necesitamos éxitos, pues esto nos anima a luchar por más éxitos” (en Torres Núñez, 1996: 25).

\subsection{El juego de simulación o drama}

Los juegos de simulación o de dramatización constituyen una de las prácticas más explotadas en el aula de la enseñanza de una lengua extranjera. De hecho, en los métodos, hay una gran representación de este tipo de actividades y representan uno de los grandes pilares sobre los que se apoya la enseñanza y práctica de la expresión oral. Se trata de un tipo de tarea realizada en parejas o grupos reducidos de hasta seis personas. Se podría distinguir entre el juego de dramatización abierto y el juego de dramatización semidirigido. Ambos requieren por parte del alumno la creación y escenificación de una situación comunicativa determinada. La diferencia radica en que en los juegos de rol abiertos tan sólo se ofrece al alumno una pequeña 
reseña situacional a partir de la cual debe improvisar un diálogo. En cambio, en el juego de dramatización semidirigido, la reseña situacional se acompaña de unas herramientas lingüísticas para que éste se sirva de ellas en el diálogo a realizar. No obstante, en los métodos, existe una mayor presencia de juegos de dramatización abiertos acompañados en menor medida por otros semidirigidos. Veamos dos ejemplos de ambos tipos de juegos de rol:

\section{Ejemplo1: juego de rol abierto}

Ahora, en grupos de tres estudiantes, buscáis varios objetos que estén en la clase (una silla, varios relojes, un bolso, etc...). Dos de vosotros simularán querer comprarlo/s. Uno de vosotros simulará ser el vendedor. (Intercambio: 69).

\section{Ejemplo2: juego de rol semidirigido}

Se trata de que los alumnos practiquen la expresión de sentimientos y actitudes dramatizando una serie de situaciones. [...] Los alumnos, en grupos, tienen que dramatizar la situación que se les propone. Se les da un tiempo para que preparen una pequeña obra de teatro que después representarán delante de sus compañeros. [...]

\section{Un poco de ayuda...}

Estoy pensando en...

Es divertido que...

¡Qué pena!

¿Qué te pasa?

Estoy furiosísimo...

¿Qué raro!

Estoy contento con...

Tengo miedo de...

Me encuentro muy deprimido...

Entiendo que... (¡Exprésate!: 57)

El libro de de Luis Rodrigo y Milagros Ortega sobre Técnicas dramáticas para la enseñanza del Español (1997) es un valioso material en este sentido. Especialmente interesante es el tratamiento más corporal de las actividades que proponen. Muchas de ellas comportan un trabajo de expresión corporal, de desinhibición, de mímica, lo que permite trabajar la implicación de todo el cuerpo en el acto de comunicación e integrado a una lengua determinada.

El juego de dramatización abierto y, en menor medida, el semidirigido están muy explotados en los métodos de enseñanza de lenguas extranjeras. Creemos que este tipo de actividad se muestra necesario y pertinente siempre y cuando el método o profesor ponga en práctica igualmente toda una serie de actividades orales para trabajar separadamente las estructuras gramaticales y léxico que el alumno debe adquirir. Si, al contrario, tan sólo se trabaja la expresión oral con el juego de rol abierto, se está propiciando que el alumno utilice siempre las estructuras y vo- 
cabulario con los que se siente seguro y que por el contrario no practique aquellos que aún no domina y con los que se siente en terreno movedizo. Por otra parte, el juego de rol semidirigido tampoco ayuda a integrar unas construcciones lingüísticas determinadas dado que tan sólo ofrece unas exiguas estructuras, frases o léxico sin ningún ánimo de sistematización. Ésta es la razón por la que estos tipos de ejercicios más libre deberían ser puestos en práctica tras un trabajo que nosotros hemos denominado juego de dramatización dirigido, no incluido en los manuales de enseñanza de una lengua extranjera, y que nosotros proponemos en este estudio como una práctica efectiva en la adquisición de ciertas estructuras lingüísticas y/o léxico hacia una naturalidad en su uso en la lengua oral.

El juego de dramatización dirigido se constituye de tal forma que el alumno se ve forzado a utilizar un determinado tipo de estructuras y/o léxico como forma de sistematización. Véase, a continuación, un ejemplo como botón de muestra de un posible juego de dramatización dirigido.

En la enseñanza del español como lengua extranjera, una de las estructuras lingüísticas más rebeldes en su aprendizaje concierne la expresión de la hipótesis en el pasado: si + pretérito pluscuamperfecto de subjuntivo, condicional compuesto de indicativo/ pretérito pluscuamperfecto de subjuntivo (ej: "Si hubiera tenido más tiempo, me habría/hubiera preparado mejor para el examen”). Si bien es cierto que el trabajo gramatical de esta estructura no plantea problemas inicialmente, su integración y asimilación en la lengua escrita y particularmente en la expresión oral continúa siendo una tarea ardua y compleja. El juego de rol dirigido propuesto para trabajar dicha estructura fuerza al alumno a utilizarla de forma sistemática en una situación comunicativa que lo propicia. Uno de los contextos situacionales en los que esta estructura es más fructífera se nos presenta en los conflictos relacionales en los que interviene la expresión del pesar y el reproche. Es fácil imaginar diversas situaciones conflictivas en las que pudiera darse un tal intercambio de recriminaciones. Véase a modo de ejemplo el siguiente caso y la actividad de juego de rol dirigido que aquí proponemos para trabajar esta estructura hipotética.

\section{Expresión de la hipótesis en el pasado}

si + pretérito pluscuamperfecto de subjuntivo, condicional compuesto de indicativo/ pretérito pluscuamperfecto de subjuntivo

Situación:

Un matrimonio en desacuerdo inicia una disputa repleta de reproches y lamentos

\section{Personajes:}

Marido y mujer 


\section{Posibles reproches y lamentos}

A. Mujer: reproches al marido

- $\quad$ No mostrarse comprensivo. Ejemplo: Si te hubieras mostrado más comprensivo, ...

- $\quad$ No ser atento y detallista

- $\quad$ No ayudar en las tareas domésticas

- $\quad$ No dedicar tiempo suficiente a la familia

- $\quad$ No ocuparse de los niños

- No aceptar a la familia política

- Tener una aventura extramatrimonial

- Etc.

Otras herramientas:

- $\quad$ Es una lástima que + subjuntivo

- $\quad$ Encuentro imperdonable que + subjuntivo

- $\quad$ Me hubiera gustado que + subjuntivo

- $\quad$ Necesitaba que + subjuntivo

- $\quad$ Es lamentable que + subjuntivo

B. Marido: justificaciones y lamentos

- Desconocer los sentimientos de su mujer. Ejemplo: Si me hubiera dado cuenta de que eras tan sensible,.../Si hubiera sabido cómo te sentías,...

- $\quad$ No tener tiempo

- Necesitar dinero y trabajar muchas horas

- Sentirse desorientado

- Encontrar a su mujer fría y distante

- Pasar la crisis de los cuarenta

- Intromisión de la familia de su mujer en los asuntos conyugales

Otras herramientas:

- $\quad$ Es posible que + subjuntivo

- $\quad$ Puede ser que + subjuntivo

- $\quad$ Te prometo que de ahora en adelante...

- Piensa en los niños...

Con este ejercicio es posible sistematizar una estructura de cierta complejidad como es la frase hipotética en el pasado. Una estructura que se resiste en el plano oral aunque pueda ser comprendida y bien aplicada en el plano gramatical y escrito. Tras este ejercicio, se podrían proponer otros juegos de dramatización abierta invitando a los alumnos a reutilizar esta estructura más libremente.

Como hemos podido apreciar a lo largo de este apartado, la práctica oral a partir de los juegos de dramatización o de representación de una obra teatral permite poner en funcionamiento los diferentes componentes de la competencia gramatical -léxico, pronunciación, gramática-, de la competencia sociolingüística -reglas socioculturales del uso de la lengua, sensibilidad a los registros, a la naturalidad o interpretación de las referencias culturales y del lenguaje figurado-, de la compe- 
tencia discursiva -el diálogo con sus elementos de cohesión y coherencia- así como de la competencia estratégica -como compensar faltas o lapsus.

A continuación, nos centraremos en el teatro como modelo, una práctica en que el estudiante adopta un papel de receptor en tanto que espectador. Para ello, analizaremos un caso histórico que nos permitirá observar cuáles son las competencias abordadas y el enfoque didáctico en esta propuesta para la enseñanza/aprendizaje del español lengua extranjera.

\section{HABLAMOS ESPAÑOL: DE LA DRAMATIZACIÓN COMO MODELO SOCIOCULTURAL Y LINGÜÍSTICO}

Entre 1970 y 1971, la televisión alemana NDR rueda en Hamburgo la serie Hablamos Español. Compuesta de 39 capítulos, el objetivo de dicha producción es la enseñanza del español como lengua extranjera con la escenificación de diversas situaciones de la vida cotidiana. Estas dramatizaciones permitían abordar tanto aspectos lingüísticos -gramática y léxico- como aspectos sociolingüísticos en relación con el uso de la lengua en contexto y la cultura española. Hablamos Español representa una de las primeras tentativas de estas características en el campo de la enseñanza-aprendizaje del español como lengua extranjera.

Para la elaboración del material didáctico, la serie contó con el asesoramiento lingüístico de José María Navarro. En cuanto a la interpretación de los distintos capítulos, la televisión alemana contrató a actores de nacionalidad española y se puso en contacto primeramente con el hoy reconocido actor y director de teatro español José Luis Gómez y más tarde con los actores y actrices de la prestigiosa compañía teatral Els Joglars. En la entrevista realizada en 2010, José Luis Gómez nos cuenta el inicio de esa colaboración con la TV alemana: "Cuando yo ya estaba en Alemania decidiendo volver a España, me ofrecieron hacer una serie de televisión en Hamburgo, Hablamos Español, y, como quería estar bien acompañado, recomendé a Joglars” (Corral, 2011: 10). Asimismo, Albert Boadella, director y dramaturgo de Els Joglars recuerda aquella experiencia muchos años más tarde:

Cuando aterrizaba en el aeropuerto de Hamburgo, me asaltaba el deseo de volver a casa. Me había dejado convencer por mi amigo José Luis Gómez para que aceptara una prueba de actuación para trabajar en la serie de televisión alemana "Hablamos español”. Como indicaba el título, se trataba de enseñar el español a través de 39 capítulos, dramatizados en muy diversas situaciones. El asunto parecía previamente bastante insulso, pero, en cambio, las condiciones económicas resultaban ser muy sustanciosas. [...] ... estuve a punto de mandarlo todo al carajo, pero la tentación del dinero era decisiva, y se convirtió en la única vez que he hecho algo relacionado con la escena exclusivamente por razones económicas.

Después, el asunto fue mucho más interesante de lo que había previsto; los guiones eran obviamente bastante mediocres y el trabajo más bien monótono, pero nuestra presencia en todo aquel montaje creó momentos inolvidables (Boadella, 2001: 193194). 
Como se deduce de la cita de Boadella, el rodaje de una serie de estas características no casaba con los intereses y el tipo de teatro que la compañía practicaba. Por otra parte, la valoración que éste hace de los guiones de la serie ("eran obviamente bastante mediocres") nos ofrece una primera pista sobre la calidad de la misma desde el punto de vista dramatúrgico. Ahora bien, ¿esa "mediocridad" dramatúrgica implica forzosamente insuficiencias en el enfoque didáctico de la propuesta? Veamos seguidamente la estructura de la serie desde una perspectiva pedagógica. Para ello, hemos tomado como botón de muestra el último capítulo de esta producción.
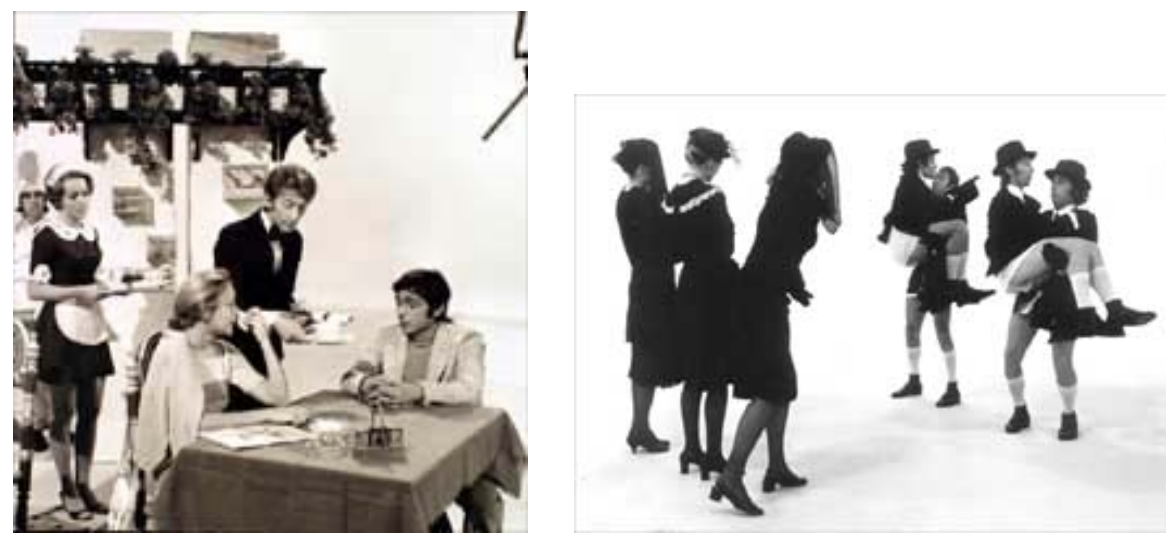

Imágenes de la serie Hablamos Español (Archivo de Els Joglars)

El capítulo 39 está compuesto de seis cuadros completos y una conclusión. Cada una de las escenas muestra una situación y contexto determinados y son presentadas en grupos de dos, a las cuales sucede una explicación gramatical. De este modo, tenemos tres grupos de dos secuencias cada uno más un colofón:

- $\quad$ escenas 1 y 2

o explicación gramatical

- $\quad$ escenas 3 y 4

o explicación gramatical

- $\quad$ escenas 5 y 6

o explicación gramatical

- colofón del capítulo.

La primera secuencia se sitúa en un espacio al aire libre y recrea una visita turística en la que un guía muestra a los visitantes extranjeros una célebre torre y casti- 
llo construidos por los moros. El diálogo está en su mayor parte formado con enunciados en la forma pasiva:

Esta torre fue construida en el siglo IX por los moros

La hija de un rey moro de Toledo fue encerrada por su padre

La princesa fue liberada por su amante

La leyenda ha sido publicada

La torre ha sido restaurada.

La segunda escena se desarrolla esta vez en un espacio cerrado. Un agente inmobiliario muestra una villa en venta a un matrimonio americano. De igual modo que en el cuadro anterior, las réplicas de los personajes están repletas de frases en la forma pasiva:

La casa y el parque fueron vendidos en 1928

¿Cuándo fue construida la casa?

Fue restaurada en el año 1921

El parque fue vendido por el actual propietario

Muchos castillos y casas antiguas han sido transportados a América.

Tras la presentación de estas dos escenas, se procede a un resumen gramatical. Se muestra por escrito alguna de las frases anteriores acompañadas posteriormente por una traducción oralizada en alemán y una explicación explícita sobre la construcción pasiva en lengua castellana: ser + participio pasado y concordancia de este último con el sujeto de la frase. Luego, otras frases modelo tienen la función de mostrar el complemento agente introducido con la preposición por.

La escena tres y cuatro tienen como objetivo introducir la frase pasiva refleja en español, denominada también impersonal pasiva. La primera se desarrolla en la recepción de un hotel en la que aparecen un recepcionista y los mismos turistas de la primera secuencia. Las frases son un muestrario de este tipo de construcción:

La comida se sirve de $13: 30$ a 15

En España se come muy tarde

El desayuno se sirve de 8 a 10 de la mañana.

Luego, la cuarta escena continúa con la misma temática gramatical aunque aporta escasos ejemplos a los ya aludidos. Cabe hacer mención, no obstante, del marcado carácter paródico que envuelve esta secuencia, lo cual otorga cierto toque desenfadado al conjunto. Toda la escenografía y vestuario del cuadro se caracterizan por un blanco nuclear. Una gran mesa rectangular se erige como único elemento de mobiliario. En ella, un hombre, cuyo rostro refleja el hastío, no deja de repetir 
¡Tengo hambre! Al otro lado de la mesa, un grupo formado por dos hombres y dos mujeres, cantan al Señor para hacer la espera de la comida algo más llevadera. Las réplicas siguen presentando enunciados en los que aparece la forma pasiva refleja:

Tenga usted paciencia. La comida se sirve de 13:30 a 15.

En España se come muy tarde

Aquí, se canta mucho y se come poco.

Concluidas estas dos escenas, se procede nuevamente a la explicación gramatical siguiendo el mismo protocolo mencionado anteriormente.

Por último, los dos cuadros finales muestran respectivamente dos tópicos de la cultura española: la fiesta y la ignorancia de ciertos agentes de seguridad. En la primera, se presenta una fiesta de amigos en la que beben, comen, juegan y cantan. La escena se centra en el léxico, la pronunciación y la ortografía de forma no demasiado sistemática. De este modo, tomando como punto de partida el juego de las prendas, los presentes deben encontrar palabras que empiecen por "z", lo cual permitirá igualmente el tratamiento del error. Se enumeran los términos zapatos, zapatillas, zuecos y "cemento", incidiendo así en algunos errores más comunes. Por otra parte, se escuchan algunas canciones conocidas estrechamente asociadas a la cultura hispana. En cuanto al último cuadro, se escenifica el encuentro y diálogo entre un agente de seguridad y un arqueólogo en su excavación. Este introduce alguna que otra frase pasiva más pero sin ningún ánimo de sistematización marcando, eso sí, un carácter paródico al conjunto.

Al término de las dos últimas escenas, se procede a hacer un resumen gramatical de todo lo expuesto anteriormente según el siguiente modelo:

Frase activa: Los moros construyeron esta torre Frase pasiva: Esta torre fue construida por los moros Frase activa: Servimos el desayuno de 8 a 10.

Frase pasiva refleja: El desayuno se sirve de 8 a 10.

Cierra este apartado la presentación de unas cuantas frases escritas y oralizadas seguidas de un silencio para que el espectador pueda repetirlas de forma autónoma.

La serie se acaba con un colofón, una corta secuencia en la que aparece nuevamente la fiesta de la escena $5 \mathrm{y}$ en la que todos los presentes cantan, beben y bailan flamenco despidiéndose con la canción "Adiós muchachos, compañeros de mi vida...”.

$\mathrm{Al}$ margen de las cuestiones lingüísticas presentadas en este capítulo, cabe subrayar el tono burlesco y paródico que imprime a todo el conjunto un aire desenfadado. Este hecho no es de extrañar dado que Els Joglars se definen justamente por la parodia, la crítica y el humor que impregnan cada una de sus obras. Por otra parte, el momento en que se realizó dicha serie coincide con los primeros años de la compañía, una etapa en la que el mimo y la expresión corporal eran los pilares 
sobre los que se apoyaba su teatro. Esto queda bien patente en este capítulo, no tan sólo por un uso de la gestualidad claramente inspirada en el mimo sino también por la austeridad en la escenografía y en el vestuario en la mayor parte de los cuadros presentados.

Desde el punto de vista didáctico, la serie no deja de ser muy rudimentaria. De entrada, se observa un intento de sistematización en lo que concierne a la estructura gramatical de la frase pasiva en español, lo cual no siempre queda suficientemente manifiesto. Por otra parte, el léxico presentado es muy pobre y poco desarrollado, y la secuencia consagrada a la ortografía no deja de ser una pura anécdota. En lo referente a la pronunciación y entonación, los modelos que se presentan son muy artificiales, haciendo uso de una dicción en exceso ralentizada y marcada, lo que confiere al conjunto un efecto de falsedad notorio. En fin, los aspectos socioculturales propuestos en este capítulo reposan en su mayor parte en tópicos y estereotipos asociados a la cultura española. Ahora bien, no creemos que este hecho represente un obstáculo en sí mismo siempre y cuando se aportaran simultáneamente otros aspectos socioculturales relevantes para la definición del pueblo español.

No obstante, la propuesta pedagógica de la serie Hablamos Español no debería ser subvalorada. Si bien es cierto que en los años 70, momento de su filmación, ya era conocido el enfoque comunicativo, el cual insistía en la importancia de la naturalidad y autenticidad de los documentos audiovisuales, no siempre se aplicaba éste de forma continua. Por otra parte, los métodos más desarrollados eran los manuales de francés e inglés como lengua extranjera. En lo referente al español, las investigaciones en el campo de su enseñanza como lengua extranjera se iniciaron mucho más tarde y remontan tan sólo a unos 15 o 20 años aproximadamente. Hablamos Español constituye una valiosa iniciativa, no sólo por representar en su época una innovación en el campo de la enseñanza-aprendizaje del español como lengua extranjera a partir de la dramatización de unas situaciones en contexto, sino también porque ésta, en su formato, ambiciona la integración de las competencias básicas en el acto comunicativo.

\section{CONCLUSIONES}

A lo largo de este estudio hemos abordado las funciones que asume el teatro en la enseñanza/aprendizaje de una lengua extranjera, tanto desde la participación del estudiante como actor así como de receptor. Hemos podido observar, que en sus distintas prácticas, éste pone en funcionamiento muchos de los componentes de las diversas competencias que participan en el acto comunicativo -gramatical, sociolingüística, discursiva y estratégica- y que, por lo tanto, su aplicación en el aula se revela beneficiosa y eficaz para mejorar las cuatro destrezas a desarrollar en el estudiante y, en particular, la expresión oral. En efecto, la práctica o recepción de las actividades derivadas del arte teatral permite trabajar la lengua en conjunción con otros sistemas de signos que intervienen en la comunicación oral -la voz, la expresividad facial, el gesto o el movimiento corporal- y representa, en consecuen- 
cia, una herramienta de gran ayuda para fijar de forma duradera los conocimientos. Este último aspecto está relacionado asimismo con otro factor de capital importancia para el aprendizaje: el componente afectivo. La práctica del teatro como recurso pedagógico representa un elemento dinamizador que pone en funcionamiento la emoción y afectividad del aprendiente, factores esenciales para garantizar el éxito del aprendizaje. Creemos, por lo tanto, haber presentado en este estudio algunas de las ventajas y beneficios del uso de este recurso pedagógico en el aula de enseñanza/aprendizaje de una lengua extranjera.

Ahora bien, en este trabajo no hemos abordado qué tipo de teatro se revelaría el más adecuado para la representación en el marco de la enseñanza-aprendizaje de una lengua extranjera y no quisiera concluir el estudio sin plantear esta última cuestión.

Hasta el momento, los estudiosos se han pronunciado preferentemente por un teatro realista en la educación. Torres Núñez afirma que

Nuestra experiencia ha demostrado que es difícil utilizar un texto que intenta distorsionar el significado lógico del lenguaje, con alumnos que no son actores profesionales. De aquí que comprendamos las sugerencias de Rincón y Sánchez-Enciso (1985, 54) al considerar que «el teatro del absurdo y el teatro brechtiano, implican moldes específicos de interpretación, coherentes con los postulados generales de esas dramaturgias». Para los alumnos de Enseñanzas Medias recomiendan el «teatro realista de compromiso». Según ellos, este teatro «se aproxima bastante más a lo que [nuestros alumnos entienden] por interpretación, aunque interpretar bien no es fácil ni mucho menos»" (1993: 333).

Sin embargo, tras haber analizado el capítulo número 39 de la serie Hablamos Español, una nueva cuestión se nos plantea. Esta producción y propuesta pedagógica se caracterizaba por la presencia de una cierta sorna en la interpretación de los actores y por una tenue parodia que provocaba un efecto de distanciamiento en el espectador. Evidentemente podemos poner en duda la eficacia educativa de ese distanciamiento si utilizamos dicho material como método de aprendizaje en tanto que receptores/espectadores/aprendientes de una lengua extranjera. Ahora bien, en el marco de una dramatización llevada a cabo por los estudiantes, me pregunto si justamente el aspecto paródico o burlesco de una obra teatral o de una única secuencia no presenta más bien ventajas para el aprendizaje de las lenguas extranjeras. Lo burlesco y paródico suele reposar en una magnificación y exageración de algunos caracteres de los personajes. ¿Esa exageración no podría representar un punto de apoyo para los estudiantes, por ejemplo, en la mejora de su pronunciación y entonación? A través de la exageración, ¿no sería ésta una vía para encontrar el punto medio y justo que se situaría entre la producción poco adecuada del estudiante y la caracterización extrema de un prototipo a través de lo bufonesco, paródico y burlesco? Dejo esta cuestión abierta como motivo para una reflexión más profunda en estudios posteriores. 


\section{REFERENCIAS BIBLIOGRÁFICAS}

AUBIN, Sophie (1996): La didactique de la musique du français : sa légitimité, son interdisciplinarité. Tesis doctoral, Université de Rouen en Francia.

AUBIN, Sophie (2008): "Pourquoi enseigner les musiques de langue-culture?" en Musiques, langues, cultures et didactique pour l'apprentissage de la compréhension humaine. Synergies Espagne 1, 41-46.

BAETENS BEARDSMORE, Hugo (2003): "Variables macrologiques des programmes d'éducation bilingue en Europe” en A. Borell (ed): Cahiers du Centre Interdisciplinaire des Sciences du Langage. Actes du XIIIe Colloque International SCAV, "Recherches et procédures récentes en phontique formations plurilingues, Université de Toulouse-le-Mirail.

BAKER, C. (2001): Foundations of Bilingual Education and Bilingualism, Philadelphia, Multilingual Matters Ltd.

BERTAUX, Patricia (2000): "Utiliser les langues pour apprendre, apprendre en utilisant les langues" en Marsh David \& Langé Gisela ( eds) : Using languages to learn and learning to use languages, Jyväskylä, Finland, UniCOM, University of Jyväskylä.

BOADELLA, Albert (2001): Memòries d'un bufó. Madrid, Editorial Espasa Calpe, S.A.

BROOK, Peter (2009) : Avec Grotowski, Arles, Actes Sud-Papiers, collection Apprendre.

CORRAL, Anna (2008) : "Méthodologie musicale et enseignement-apprentissage du FLE” en Musiques, langues, cultures et didactique pour l'apprentissage de la compréhension humaine. Synergies Espagne 1, 141-152.

CORRAL, Anna (2009): Música y dramaturgia: dramaturgia musical y escenográfica en Els Joglars. Tesis doctoral, Universidad Autónoma de Barcelona en España.

CORRAL, Anna (2011): “Entrevista: José Luis Gómez, actor y director de escena. Si no hubieran existido Joglars y Boadella en la época en que surgieron, habría que haberlos inventado", Ínsula.

COYLE, Do (2002): "Relevance of CLIL to the European Commision's Language Learning Objectives" en Marsh David (ed): CLIL/EMILE -The European Dimension. Actions, Trends and Foresight Potential, Jyväskylä, Finland, UniCOM, Continuing Education Centre, University of Jyväskylä.

DORREGO, Luis y Milagros Ortega (1997): Técnicas dramáticas para la enseñanza del español, Madrid, Servicio de Publicaciones de la Universidad de Alcalá de Henares.

GENET, Jean (1979 [1956]) : Le balcon, Paris, Éditions Gallimard, Collection Folio. 
GOITIA, Leyre (2007): Actas del III Foro de Profesores de Español como Lengua Extranjera, Valencia, Web http://www.uv.es/foroele/foro3/Actas_III_Foro_ELE.pdf, 103-110.

GOMBROWICZ, Witold (1973 [1966]): Opereta, Barcelona, Barral Editores.

Hablamos Español, 1970-1971: Serie de 39 capítulos, Alemania, NDR TV.

HAYES, S. K. (1984): Drama as a Second Language: A practical guide for language teachers, Cambridge, National Extension Collage.

LECOQ, Jacques (2009 [1997]). El cuerpo poético, Barcelona, Alba Editorial.

MARTÍNEZ, Ana (2007): Actas del III Foro de Profesores de Español como Lengua Extranjera, Valencia, Web http://www.uv.es/foroele/foro3/Actas_III_Foro_ELE.pdf, 143-154.

MIQUEL, Lourdes y Neus Sans (2000): Intercambio, Madrid, Difusión.

PIAGET, J. (1962): Play, Dreams, and imitation in childhood, New York, Norton.

RUIZ, Rafael y Juan Antonio Martínez (eds.) (1996): Propuestas metodológicas para la enseñanza de las lenguas extranjeras. Texto dramático y representación teatral, Granada, Servicio de publicaciones de la Universidad de Granada.

ROLDAN, Reyes y Beatriz Tarancón (2010): ¡Exprésate! Actividades de expresión oral para la clase de ELE, Madrid, SGEL.

STANISLAVSKI, Constantin (1975 [1949]): La construcción del personaje, Madrid, Alianza Editorial, S.A.

TORRES NÚÑEZ, Juan José (1993): “Drama versus teatro en la educación”, Cauce 16, 321-334.

TORRES NÚÑEZ, Juan José (1996): Nuevos horizontes para el teatro en la enseñanza de idiomas, Almería, Universidad de Almería, Servicio de publicaciones. WESSELS, Charlyn (2000 [1987]): Drama, Oxford, Oxford University Press. 